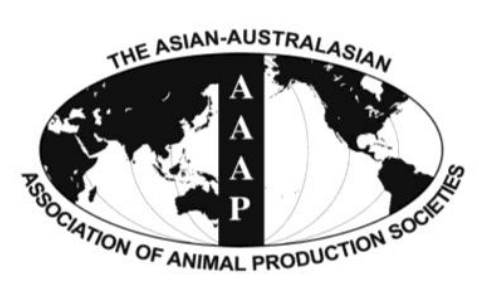

\title{
Nanotechnology in Meat Processing and Packaging: Potential Applications - A Review
}

\author{
Karna Ramachandraiah, Sung Gu Han ${ }^{1}$, and Koo Bok Chin* \\ Department of Animal Science and Functional Food Research Center, \\ Chonnam National University, Gwangju 500-757, Korea
}

\begin{abstract}
Growing demand for sustainable production, increasing competition and consideration of health concerns have led the meat industries on a path to innovation. Meat industries across the world are focusing on the development of novel meat products and processes to meet consumer demand. Hence, a process innovation, like nanotechnology, can have a significant impact on the meat processing industry through the development of not only novel functional meat products, but also novel packaging for the products. The potential benefits of utilizing nanomaterials in food are improved bioavailability, antimicrobial effects, enhanced sensory acceptance and targeted delivery of bioactive compounds. However, challenges exist in the application of nanomaterials due to knowledge gaps in the production of ingredients such as nanopowders, stability of delivery systems in meat products and health risks caused by the same properties which also offer the benefits. For the success of nanotechnology in meat products, challenges in public acceptance, economics and the regulation of food processed with nanomaterials which may have the potential to persist, accumulate and lead to toxicity need to be addressed. So far, the most promising area for nanotechnology application seems to be in meat packaging, but the long term effects on human health and environment due to migration of the nanomaterials from the packaging needs to be studied further. The future of nanotechnology in meat products depends on the roles played by governments, regulatory agencies and manufacturers in addressing the challenges related to the application of nanomaterials in food. (Key Words: Nanotechnology, Nanomaterials, Meat Products, Application, Challenges, Risks)
\end{abstract}

\section{INTRODUCTION}

With consumers demanding higher quality meat products at affordable prices and growing competition, the meat production sector has witnessed an exceptional change in not only the ingredients, but also the processing system (Weiss et al., 2010). The demand for sustainable production of meat products and emphasis on human health and wellness has further led to the growth of innovation in the meat product industry (Young et al., 2013). Thus, expectations have risen regarding the use of ingredients and additives with improved functionality to enhance the quality

\footnotetext{
* Corresponding Author: Koo Bok Chin. Tel: +82-62-530-2121, Fax: +82-62-530-2129, E-mail: kbchin@chonnam.ac.kr

${ }^{1}$ Department of Food Science and Biotechnology of Animal Resources, College of Animal Bioscience and Technology, Konkuk University, Seoul, 143-701, Korea.

Submitted Aug. 8, 2014; Revised Nov. 6, 2014; Accepted Nov. 26, 2014
}

and image of muscle foods (Olmedilla-Alonso et al., 2013). Some of the most commonly used additives in meat and poultry are antioxidants (e.g., butylated hydroxytoluene [BHT], butylated hydroxyanisole [BHA] and tocopherols), binders (e.g., carrageenan, sodium caseinate), thickeners (e.g., gelatin), humectants (e.g., sodium salt, glycerine), curing agents (sodium erythorbate, sodium nitrite and nitrate), flavor enhancers (e.g., monosodium glutamate), tenderizing enzymes (bromelin, ficin and papain) and sweeteners (e.g., corn syrup) (USDA, 2008). Although they are still in widely used, growing health concerns has caused a shift in the focus towards the development of novel meat products with reduced amounts of saturated fats, sodium salts, color fixatives (e.g., nitrites), and cholesterols, along with increased use of ingredients which have positive effects on health. It is also expected that novel products developed with new ingredients and processing systems should possess similar gustatory, visual and aromatic effects 
as traditional meat products (Weiss et al., 2010).

Hence, bioactive materials providing health benefits are increasingly added to foods in order to treat or prevent diseases (IFIC, 2006). However, there are impediments in the production, storage and distribution of foods with incorporated bioactive components. Owing to the range of traditional meat products, the impediments are likely far bigger in the meat industry. A significant challenge is the low bioavailability of bioactive components when included in meat products, mainly due to relatively elevated levels of proteins, fats, and minerals. Consequently, modifications have been attempted to the formulations of meat products, but these have often led to unfavorable effects, such as poor organoleptic quality, lowered capacity to retain water and poor resistance to the growth of microbes (Weiss et al., 2010). Therefore, the meat industry needs to implement and support an innovation agenda to address such challenges and ultimately improve the quality experienced by consumers (Troy and Kerry, 2010). Thus, nanotechnology is one such process-based innovation that could have a significant impact on the food industry (Linton and Walsh, 2008).

Nanotechnology can be referred to as an area of science and technology focused on the manufacture of nano-sized materials (less than $100 \mathrm{~nm}$ in diameter at least one dimension) that possess unique and novel properties, although a globally accepted definition does not exist (Lövenstam et al., 2010; Gruère, 2012). It also refers to the production, characterization, and manipulation of such materials (Weiss et al., 2006). The major differences between nanomaterials and bulk materials are the changes in physicochemical (e.g., porosity), optical, mechanical and catalytic properties. Other differences are also observed in the strength, absorption, function, weight, and stabilization of materials (Cockburn et al., 2012). All of these properties make nanotechnology very promising, and have led to the development of many innovations in the area of food packaging (Sozer and Kokini, 2009; Rhim et al., 2013). However, when this generic technology is applied to foods, the changed properties of the nanomaterials may also affect the behavior and properties of the foods (Cockburn et al., 2012). Nonetheless, decreased use of certain food ingredients due to the improved bioavailability of functional compounds can be achieved through the use of nanomaterials (Weiss et al., 2006). Thus, it is also likely that the amounts of salt, sugar and preservatives can be reduced through the use of nanomaterials, while improving color, flavor and texture and thereby enhancing the sensory acceptance. Furthermore, the delivery and absorption of active ingredients and nutrients can be significantly improved (Chaudhry and Castle, 2011). Other benefits include targeted delivery, enhanced stability and absorption of the bioactive compounds, along with improved antimicrobial effects against pathogens in food that may be resistant to chemical antimicrobials (Duncan, 2011; Cockburn et al., 2012).

Nanotechnology is projected to impact the food industry mainly through the creation of nano-sized materials with novel properties, the development of novel processing methods, products and improvements in food safety and biosecurity as shown in Figure 1 (Moraru et al., 2003; 2009). Strategies for the application of nanomaterials in

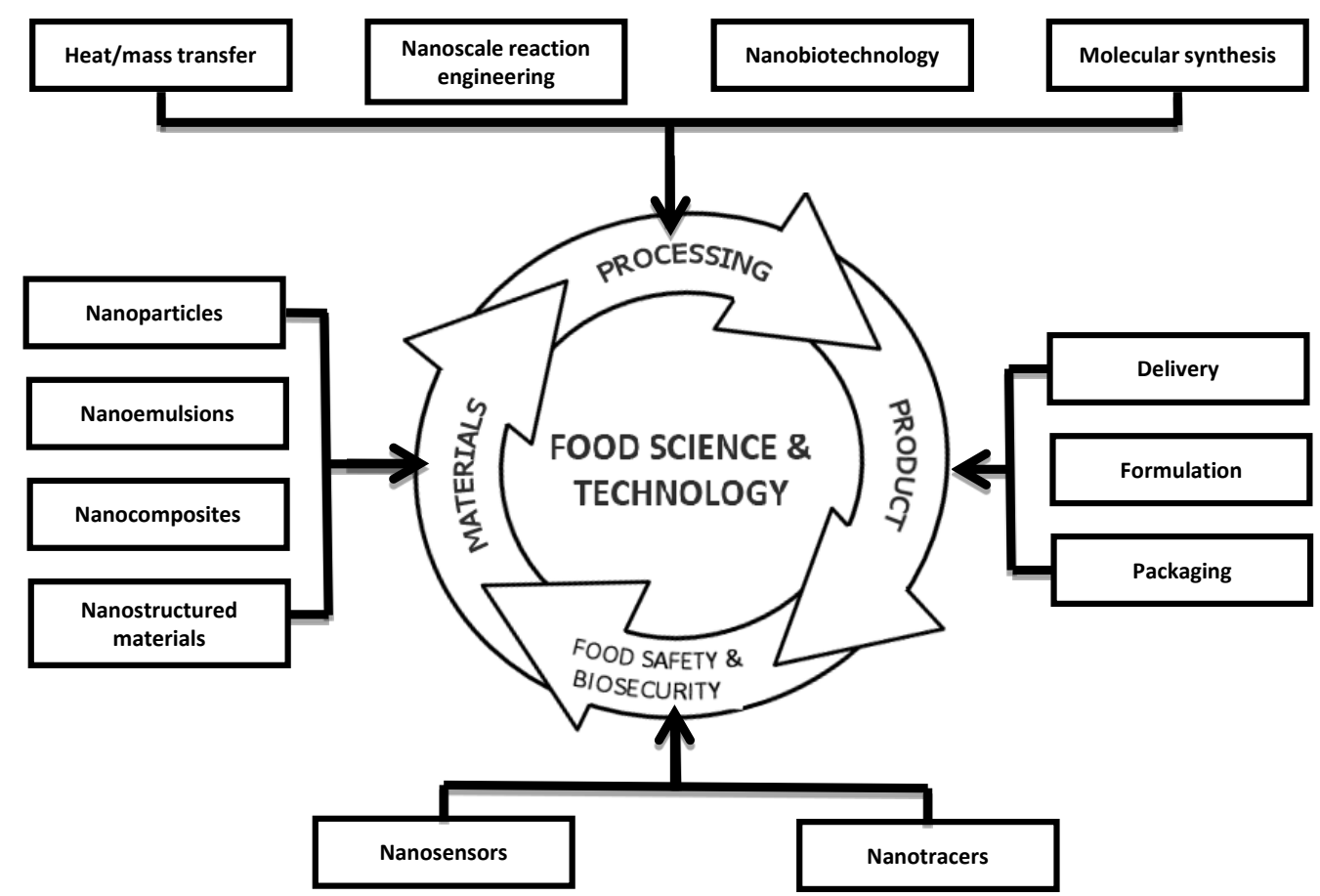

Figure 1. Application matrix of nanotechnology in food science and technology (adapted from Moraru et al. [2003]). 
food may be different from those employed in traditional nanotechnology (Weiss et al., 2006). Nevertheless, due to the novel properties exhibited by nanomaterials, significant beneficial changes are expected to be enabled in the production, packaging and distribution of many food products, including meat products (Weiss et al., 2006; Duncan, 2011; Gruère, 2012). On the other hand, this novel technology may also have the potential to cause risks to human health and the environment due to the same properties which offered its benefits (O'Brien and Cummins, 2010; Chaudhry and Castle, 2011). The perception of such risks and benefits may influence the acceptance to consumers of using this technology (Troy and Kerry, 2010). This review focuses on the types of nanomaterials, delivery systems and the risks associated with nanomaterials in areas of meat processing and packaging.

\section{MANUFACTURING NANOMATERIALS}

Nanomaterials can be produced through the utilization of two broad approaches known as top-down and bottom-up. The top-down approach is mostly used for processing inorganic materials through traditional methods such as milling, grinding, sieving, and chemical reactions (Cockburn et al., 2012). Homogenization is an example of a top-down method that utilizes pressure to reduce the size of materials such as fat globules. Milling mechanically reduces the size of materials to improve their functionality (Cushen et al., 2012). The bottom-up approach involves the assembly of smaller molecules through self-organization, resulting in the formation of supra-molecular structures which possess novel functionalities (Cockburn et al., 2012). Solvent evaporation and layer by layer (lbl) deposition are examples of the bottom up approach (Cushen et al., 2012), which is commonly employed in food applications using components such as phospholipids (Cockburn et al., 2012).

\section{Type of nanomaterials}

The novel functions associated with nanomaterials are contingent on the type of materials and their sizes (FSAI, 2008). Examples of nanomaterials that can be manufactured into one-, two-, and three-dimensional structures are thin films, nanotubes and nanoparticles, respectively. It is not easy to classify nanomaterials due to their complex structures and diverse properties. Additionally, those structures that are produced deliberately at nanometer scale and which possess novel properties are considered as nanomaterials as opposed those structures that may be naturally present (e.g., molecules of sugar, fat) or result due to conventional methods (e.g., protein nanoparticles in ricotta cheese) (HOL, 2010). The general classification of nanomaterials is summarized in Table 1 (FSAI, 2008).

\section{POTENTIAL AREAS OF APPLICATION}

According to Chaudhry et al. (2008), application of nanomaterials in food system is primarily seen in the production of food ingredients with nanostructure and in delivery systems for supplements and nutrients. Areas of investigation in meat product include reformulation through minimizing and modifying the fat content, lowering the amount of sodium, phosphate and nitrate, and inclusion of probiotics, prebiotics and other materials, such as seaweed and walnut. In addition, improvement of bioavailability, formation of compounds that can promote health and reduction of unhealthy compounds are possible areas of study for the processing and storage of meat products (Olmedilla-Alonsoa et al., 2013).

A wide variety of ingredients exist for potential application in meat processing (e.g., fat replacers such as citrus fiber, soy protein concentrate, oat fiber, carrageenan, soy fiber and plasma protein). Other areas of application include: modification of the fat profile with fish oil extract, flaxseed and linseed; salt reduction by utilization of edible seaweeds and apple pulp; nitrite reduction with the use of celery and spinach juice; delivery of novel antioxidants from rosemary extract, ascorbic acid and hyssop extract; and utilization of nisin, rosemary and oregano oil as antimicrobials (Weiss et al., 2010). Some of these areas may potentially benefit from the use of nanotechnology by the delivery of antioxidants and antimicrobials through nanomaterial in processed meats (Ozimek et al., 2010). However, the behaviors of both native and altered food in the assembly its components need to be understood for the production of nanomaterials (Augustin and Sanguansri, 2009).

\section{Nanoscale ingredients}

Ingredients produced by nanotechnology can be utilized to improve the taste and texture of food, and to increase the bioavailability of bioactive compounds and nutrients (Chaudhry et al., 2011). They can also be used to mask unpleasant flavors and odors (Cushen et al., 2012). Dry and wet milling of organic materials may result in the production of nano-sized or ultrafine powders (sizes of 100 $\mathrm{nm}$ to $1 \mu \mathrm{m}$ ) which can be utilized in food manufacturing at a low cost (Borm et al., 2006; Zhu et al., 2010). An example is nanotea (green tea), which was shown to have increased antioxidant activity due to its reduced particle size (Shibata, 2002). Other examples include ultrafine milled antimicrobial chitosan nanopowder, with increased hypolipidemic activity, and wheat bran, with improved bioactivity (Zhu et al., 2010; Zhang et al., 2013). Reducing ginger, which is sometimes used in meat as a tenderizer and extender, to micro-sized powders, was found to improve its penetrability, while also making it more soluble and 
Table 1. Types of nanomaterials, products and application

\begin{tabular}{|c|c|c|c|c|}
\hline Category & Nanomaterials & Application/function & Product name & Web address or reference \\
\hline Inorganic & Iron $(\mathrm{Fe})$ & Improved bioavailability & $\begin{array}{l}\text { SunActive iron } \\
\text { (High vive fortified fruit } \\
\text { juice) }\end{array}$ & $\begin{array}{l}\text { http://www.highvive.com/ } \\
\text { sunactiveiron.htm }\end{array}$ \\
\hline \multicolumn{5}{|l|}{ Nanoparticles } \\
\hline & Silver (Ag) & $\begin{array}{l}\text { Improved bioavailability } \\
\text { and antimicrobial activity }\end{array}$ & $\begin{array}{l}\text { Ag nanoparticles } \\
\text { (fresh food bag) }\end{array}$ & Huang et al., 2011 \\
\hline & Iridium & & & \\
\hline & $\begin{array}{l}\text { Platinum } \\
\text { Zinc }\end{array}$ & Improved bioavailability & & \\
\hline \multirow[t]{3}{*}{$\begin{array}{l}\text { Organic } \\
\text { Nanoparticles }\end{array}$} & Liposomes & $\begin{array}{l}\text { Bioactive agent. } \\
\text { Nanoencapsulation. } \\
\text { Improved solubility and } \\
\text { bioavailability, cell-specific } \\
\text { targeting. }\end{array}$ & $\begin{array}{l}\text { Lypo-spheric vitamin C } \\
\text { (Livon labs) }\end{array}$ & $\begin{array}{l}\text { http://www.livonlabs.com/cg } \\
\text { i-bin/start.cgi/liposome- } \\
\text { encapsulated/lypo-spheric- } \\
\text { vitamin-c.html }\end{array}$ \\
\hline & Protein & $\begin{array}{l}\text { Nanoencapsulation of } \\
\text { hydrophobic nutraceuticals. } \\
\text { Improved functionalities } \\
\text { (gelation, heat stability) }\end{array}$ & Casein micelle & Semo et al., 2007 \\
\hline & Polymeric & $\begin{array}{l}\text { Nanoencapsulation \& } \\
\text { improved functionalities } \\
\text { (delivery, antimicrobial) }\end{array}$ & $\begin{array}{l}\text { Chitosan/ } / \text {-lactoglobulin } \\
\text { nanoparticles }\end{array}$ & Chen and Subirade, 2005 \\
\hline Nanofibres & Globular proteins & $\begin{array}{l}\text { Improved functionalities } \\
\text { (Thermal stability, thickening } \\
\text { agent, shelf life) }\end{array}$ & $\begin{array}{l}\text { Antioxidants } \\
\text { zein prolamine } \\
\text { nanofibers }\end{array}$ & Fernandez et al., 2009 \\
\hline \multirow[t]{2}{*}{ Nanoemulsions } & $\begin{array}{l}\text { Oil in water } \\
(\mathrm{o} / \mathrm{w})\end{array}$ & $\begin{array}{l}\text { Nanoencapsulation and } \\
\text { regulated release of bioactive } \\
\text { agents and nutrients }\end{array}$ & $\begin{array}{l}\text { Curcumin } \\
\text { nanoemulsion }\end{array}$ & Huang et al., 2010 \\
\hline & $\begin{array}{l}\text { Water in oil } \\
(w / o)\end{array}$ & & $\begin{array}{c}\text { Ice cream } \\
\text { (nestle) }\end{array}$ & Möller et al., 2009 \\
\hline Nanodispersions & Beta- Carotene & $\begin{array}{l}\text { Improved solubility and } \\
\text { addition levels }\end{array}$ & $\begin{array}{l}\text { Beta- Carotene } \\
\text { nanodispersions }\end{array}$ & Tan and Nakajima, 2005 \\
\hline Nanoclays & $\begin{array}{l}\text { Montmorillonite } \\
(\mathrm{mmt})\end{array}$ & $\begin{array}{l}\text { Improved properties in } \\
\text { packaging (barrier, thermal, } \\
\text { durability) }\end{array}$ & $\begin{array}{l}\text { Montmorillonite (mmt) } \\
\text { nanocomposite }\end{array}$ & Avella et al., 2005 \\
\hline
\end{tabular}

Adapted from FSAI (2008).

dispersible than native ginger (Zhao et al., 2009). If such ingredients were further reduced to nanopowders, they may exhibit novel physical and chemical properties. Although powders with particles in nanometer range may have enormous potential, further improvements in understanding of the nature of raw materials (e.g., toughness) and advancements in equipment are required for successful application (Zhu et al., 2010). The area of nanotechnologybased ingredients is still in the nascent stage, and the extensive use of nano-sized ingredients in food is predicted with the development of other associated technologies (Cushen et al., 2012).

\section{Nanoencapsulation}

Most ingredients meant to serve special functions in food are not incorporated in their original form, making it necessary to modify these materials prior to use with suitable delivery systems (Weiss et al., 2006). For instance, many bioactive compounds are sensitive to temperature, oxidation, and lack of solubility in water along with the preference for loci in the gastrointestinal tract for entry into the blood stream through absorption (Shimoni, 2009). Therefore, a delivery system must transport the functional ingredient to its target while simultaneously protecting it from oxidative degradation (Weiss et al., 2006). Furthermore, the release of functional ingredients can be regulated by the strength of ions, as well as the surrounding temperature and $\mathrm{pH}$. It is also important that the ingredients be compatible with the qualitative aspects of foods, such as color, texture, taste etc. Although several delivery systems exist, only a few systems (e.g., association colloids, biopolymeric nanoparticles, and nanoemulsions) are likely 
to have a broad impact on food production (Weiss et al., 2006). Association colloids are a stable system with welldispersed nanoparticles in the product. Micelles and reverse micelles are good examples of this type of colloidal system. In the colloidal system, the novel properties of particles ( 5 to $100 \mathrm{~nm}$ ) can be delivered through the use of materials that may be polar, nonpolar and amphiphilic, thereby improving the shelf life of the food along with providing other benefits (Flanagan and Singh, 2006). Yusop et al. (2012) applied micelles to chicken breast fillets, where the use of nanoparticle paprika oleoresin as an ingredient seemed to enhance the effects of marination and the sensory qualities of the fillets.

Biopolymers in a nanometer scale can also be utilized to improve the shelf life of foods. An example of a food-grade synthetic biopolymer is polylactic acid (PLA), which is used as a delivery system (Weiss et al., 2006). Regulated release of the functional ingredients can also be achieved through the use of other synthetic biopolymers, such as polylactic-co-glycolic acid (PLGA) and polyethylene glycol (Gupta and Gupta, 2005). The antimicrobial activity was enhanced when PLGA nanoparticles were used as a delivery system for phenolic compounds in cooked and uncooked chicken. Inhibition of pathogenic microorganisms such as Salmonella Typhimurium, Escherichia coli O157:H7 and Listeria monocytogenes was found at very low concentrations of phenolics (e.g., benzoic and vanillic acids) when packaged in polylactic glycolic acid nanoparticles (Ravichandran et al., 2011). On the other hand, a natural alternative for synthetic biopolymer, chitosan, can also be used in the encapsulation of functional compounds (Weiss et al., 2006). Abdou et al. (2012) investigated the effects of antimicrobial chitosan nanoparticles on the growth of microorganisms in fish fingers, and found that the fish fingers with chitosan or chitosan edible coating showed decreased bacterial counts compared to the uncoated fish fingers and those with commercial coating, suggesting a potential extension of the shelf-life. Study of the rheological properties revealed coatings to be pseudoplastic in nature for all different concentrations of chitosan (Abdou et al., 2012).

Functional compounds can be included in a droplet or any other phase of nanoemulsions, such as the continuous and interfacial phases. These systems can provide a vehicle for more than one material, with activities such as antimicrobial and antioxidant functions (Weiss et al., 2006). An example of a nanoemulsion is the nanostructured multilayer emulsion, in which the release of active ingredients is dependent on external stimulus (McClements and Rao, 2011). However, the inclusion of emulsions in meat systems remains a challenge, as reported by Salminen et al. (2013). The incorporation of a stable oil-in-water $(\mathrm{O} / \mathrm{W})$ emulsion in pork sausages was observed to cause an increase in oxidation. In a study by Joe et al. (2012), a nanoemulsion made with sunflower oil was used in the processing of Indo-Pacific king mackerel steaks. They reported a decrease in the initial microbial growth up to 12 $h$ except for the control and an increase in the shelf life of $48 \mathrm{~h}$, determined organoleptically, indicating its potential use in the short-term storage of fish products. Table 2 presents the utilization of some nanomaterials for delivery, and the improved performance of functional compounds in meat systems. Nanoemulsions and micelles are two examples of delivery system that are cost effective and easy to produce (Chaudhry et al., 2008). Apart from compatibility and cost, several other disadvantages and advantages are associated with each type of delivery system for the encapsulation and regulation of the release of functional compounds (Weiss et al., 2006). Although some studies have demonstrated improved encapsulation methods, it is critical to investigate their functional efficacy of oil-in water emulsion in a complex food matrix, such as in meat products (Salminen et al., 2013).

\section{Nanotubes and nanofibers}

The idea of using nanotubes in food originates from

Table 2. Nanomaterials for delivery of functional ingredients in meat products

\begin{tabular}{|c|c|c|c|c|}
\hline Nanomaterial & $\begin{array}{c}\text { Function of } \\
\text { nanomaterial }\end{array}$ & Meat product & Performance in meat & Reference \\
\hline $\begin{array}{l}\text { Micelle } \\
\text { (Nanoparticle paprika } \\
\text { oleoresin) }\end{array}$ & $\begin{array}{l}\text { Encapsulation of } \\
\text { functional } \\
\text { ingredient }\end{array}$ & Chicken breast fillet & $\begin{array}{l}\text { Improved marinating } \\
\text { performance and sensory } \\
\text { perception }\end{array}$ & Yusop et al., 2012 \\
\hline $\begin{array}{l}\text { Biopolymeric } \\
\text { nanoparticle } \\
\text { (Chitosan nanoparticle) }\end{array}$ & Antimicrobial & Fish Finger & $\begin{array}{l}\text { Increased antimicrobial } \\
\text { activity }\end{array}$ & Abdou et al., 2012 \\
\hline $\begin{array}{l}\text { O/W Nanoemulsion } \\
\text { (Sunflower oil) }\end{array}$ & Antimicrobial & $\begin{array}{l}\text { Indo-Pacific } \\
\text { king mackerel } \\
\text { Steaks }\end{array}$ & Short lived antimicrobial & Joe et al., 2012 \\
\hline $\begin{array}{l}\text { PLGA } \\
\text { nanoparticles } \\
\text { (phenolics loaded) }\end{array}$ & Antimicrobial & $\begin{array}{l}\text { Raw \& cooked } \\
\text { meat systems }\end{array}$ & $\begin{array}{l}\text { Efficient antimicrobial } \\
\text { activity }\end{array}$ & $\begin{array}{l}\text { Ravichandran et al., } \\
2011\end{array}$ \\
\hline
\end{tabular}


carbon nanotubes (CNTs), which have numerous potential applications in materials, other than food (Weiss et al., 2006). CNTs (single-walled or multiple-walled) can be used in the detection of pathogens in food due to their ability to immobilize antibodies, along with other benefits. The large surface area of the nanotubes can be exploited to increase the sensitivity of immunosensor by up to 6-fold thereby reducing the detection limit of Staphylococcal Enterotoxin B (Yang et al., 2008). CNTs with allyl isothiocyanate in cellulose-based food packaging have been shown to have antimicrobial effects. This type of packaging inhibited the growth of Salmonella in shredded cooked chicken for up to 40 days due to the inclusion of CNTs (Dias et al., 2013).

The milk protein $\alpha$-lactalbumin, which assembles itself as a nanotube under certain conditions, has been exploited in food nanotechnology (Graveland-Bikker and Kruif, 2006). Encapsulation of functional ingredients becomes easier with increased surface to volume ratio of the materials, along with additional nutritional benefits. These nanotubes are resistant to heat and mechanical stress, and also possess improved ability for storage, gelation and viscosity (Graveland-Bikker and Kruif, 2006). Electrospinning of gelatin results in the production of gelatin nanofibers, which can be used as a more effective thickening agent in lower amounts when compared to bulk gelatin. It has also been noted that gelatin nanofibers can be utilized in the stabilization of food emulsions (Okutan et al., 2014). According to Neo et al. (2013), zein nanofibers could be loaded with antioxidants, such as gallic acids.

\section{MEAT PACKAGING: IMPROVED, ACTIVE AND SMART PACKAGING}

Food packaging materials should possess proper mechanical, thermal, and optical properties for foods. Antimicrobial and barrier functions against gases, vapor and aroma are also important as food packaging materials. The materials currently used for the packaging of food are not biodegradable, and hence cause environmental concerns. On the other hand, environment friendly packaging made of biopolymers may not have optimal mechanical and barrier properties (Rhim et al., 2013). Many investigators have indicated that the food packaging industry could significantly benefit from nanotechnology (EFSA, 2009). Major advantages of using nanotechnology for packaging include enhanced barrier, mechanical and heat-resistant properties, along with improved biodegradability and flame retardancy in comparison with conventionally used polymers (Lee, 2010). Nanomaterials can also be used in packaging to provide enhanced antimicrobial effects, and allow the detection of spoilage through nanosensors (de Azeredo, 2009).

\section{Improved packaging: Nanocomposite for improved barrier function}

Nanocomposites are formed when a polymer matrix is reinforced with fillers in the nanoscale, resulting in improved packaging properties (Silvestre et al., 2011). Some examples of fillers are clays, silicates, cellulose microfibrils, cellulose whiskers, and carbon nanotubes (de Azeredo, 2009). A few examples of polymers include polyamide, polystyrene, nylon, polyolefins etc. (Silvestre et al., 2011). However, growing demand for the production of biodegradable packaging has led to the use of biopolymers that may be natural or synthetic. Examples of natural biopolymers include chitosan, cellulose and carrageenan, while synthetic biopolymers include polyvinyl alcohol, polylactide (PLA), and polyglycolic acid (PGA) (Rhim et al., 2013). Amongst the fillers used in the nanoscale, montmorillonite is commonly exploited in nanocomposites due to its cost effectiveness, along with other advantages (Silvestre et al., 2011).

Depending on the arrangement of silicate, nanocomposites can be distinguished as intercalated, flocculated, or exfoliated nanocomposites (Weiss et al., 2006). The barrier properties of packaging are improved due to the use of nanocomposite materials which cause $\mathrm{O}_{2}$ to take a more circuitous path compared to the regular packaging (Silvestre et al., 2011). In a recent study by Picouet et al. (2014), nanoclays were used for the vacuumpackaging of beef loins. The nano-sized clays were dispersed in a polymer matrix of polyamide 6 (PA6) to form a packaging film. The addition of nanoclays into PA6 demonstrated several positive effects: elevated $\mathrm{O}_{2}$ barrier properties, capability to block UV and improved stiffness. When compared to commercial packaging, similar influences on the quality of beef were observed, with an additional advantage of lowered thickness (Picouet et al., 2014). Durethan, a meat-packaging product of Bayer, consists of a polyamide plastic film reinforced with clay nanoparticles and is able to act as an oxygen, moisture and carbon dioxide barrier (Brody et al., 2008).

\section{Active packaging: Metallic and metallic oxide nanoparticles in nanocomposite}

In comparison to molecular antimicrobials, inorganic nanoparticles without much difficulty can be incorporated into polymers, making them suitable for packaging with improved functionality (Althues et al., 2007; Duncan, 2011). However, the suitability for packaging depends on the chemical nature of nanoparticles as seen with silver nanoparticles which possess excellent antimicrobial effect whereas no such effect is seen with gold nanoparticles (Kim et al., 2007; Duncan, 2011). The mechanisms for the antimicrobial effect of silver nanoparticles reported are cellular damage by silver atoms released from the surface of 
nanoparticles, toxicity caused by silver ions released from inside of the nanoparticles and structural destruction of cellular membranes by bound nanoparticles (Morones et al., 2005; Lok et al., 2007; Duncan, 2011). Due to the wide spectrum of antimicrobial action even at small concentrations ( 2 to $4 \mu \mathrm{g} / \mathrm{mL}$ ), including activity against microbes that are resistant to conventional chemical antimicrobials, silver nanoparticles (45 to $50 \mathrm{~nm}$ ) can effectively improve the shelf-life of foods. $\mathrm{TiO}_{2}$ nanoparticles are also known for their antimicrobial properties, along with the protection of packaged food from UV damage and being optically clear (Duncan, 2011). Apart from the type of nanoparticles, size, shape, surface charge etc. are also known to determine the antimicrobial effect of nanoparticles (Duncan, 2011). Based on a study by Panea et al. (2013), zinc oxide $(\mathrm{ZnO})$ can be a potent antimicrobial along with silver $(\mathrm{Ag})$ in a nanocomposite with low density polyethylene. Pathogens in meat, such as Escherichia coli, Pseudomonas aeruginosa and Listeria monocytogenes, were inhibited by this type of packaging, based on a study on chicken breasts (Panea et al., 2013). In another study by Fedotova et al. (2010), the inclusion of silver nanoparticles in a sausage casing made of cellulose and collagen film had strong antibacterial and antifungal effects.

\section{Smart packaging: Nanodevice-combined polymers}

Food packaging consisting of polymers in conjunction with nanodevices is referred to as smart packaging. Smart packaging can be used to monitor food or the environment around it during storage and transit (Yam et al., 2005). In addition, smart packaging ensures the authenticity of the food product, providing protection against counterfeiting. Furthermore, smart packaging was originally developed with the intention of checking the integrity of the food package. The inclusion of devices is also able to track the history of time -temperature and expiration date. Devices such as nanosensors are able to detect microbes, toxins and chemicals while being incorporated in the packaging (Silvestre et al., 2011).

\section{Nanosensors}

Nanosensors have great potential to hasten the speed of detection, identification and quantification of pathogens, spoilage substances and proteins that cause allergies (Silvestre et al., 2011; NSI, 2013). Thus, nanosensors have the potential to significantly impact many sectors including food (NSI, 2013). Generally, nanosensors are placed in food packages to monitor the internal and external conditions of the food. An example of a nanosensor can be seen in the study by Mills (2005), where oxygen indicators were employed in the packaging of uncooked bacon under carbon dioxide. The change in color of the sensor inside the package was designed to indicate exposure of the food to oxygen.

The spoilage of food could be detected in the early stages, and thereby avoid several problems for food businesses and consumers. Nanosensors that employ CNTs with antibodies against Salmonella attached can be applied to detect food pathogens on the surfaces of foods, such as chicken (Villamizar et al., 2008). Another application is to detect the freshness of canned tuna, by examining the presence of indicator chemicals such as xanthine and hypoxanthine (Cubukca et al., 2007). Nanotechnology based devices are projected to have a brighter future in many areas including food although challenges in fabrication, integration and mass manufacture of such devices exist (Evans, 2009). Table 3 lists the different types of nanostructures used in the packaging of meat products.

Table 3. Nanomaterials for meat packaging

\begin{tabular}{|c|c|c|c|c|}
\hline Nanomaterial & Carrier film & Meat product & Effect & Reference \\
\hline $\begin{array}{l}\text { Montmorillonite } \\
\text { (MMT) } \\
\text { nanoclays }\end{array}$ & Polyamide 6 (PA6) & Beef loins & $\begin{array}{l}\text { (Improved packaging ) } \\
\text { Enhanced shelf life of meat } \\
\text { lowered thickness of packaging } \\
\text { material }\end{array}$ & Picouet et al., 2014 \\
\hline $\begin{array}{l}\text { Zinc oxide }(\mathrm{ZnO}) \\
+ \text { silver }(\mathrm{Ag}) \\
\text { nanoparticles }\end{array}$ & $\begin{array}{l}\text { Low density } \\
\text { polyethylene } \\
\text { (LDPE) }\end{array}$ & Chicken breasts & $\begin{array}{l}\text { (Active packaging) } \\
\text { Inhibition of } \\
\text { Escherichia coli, Pseudomonas } \\
\text { aeruginosa, Listeria monocytogenes }\end{array}$ & Panea et al., 2013 \\
\hline $\begin{array}{l}\text { Carbon nanotube } \\
(\mathrm{CNT})\end{array}$ & $\begin{array}{l}\text { Allyl } \\
\text { Isothiocyanate } \\
\text { (AIT) in } \\
\text { cellulose } \\
\text { polymer }\end{array}$ & $\begin{array}{l}\text { Cooked chicken } \\
\text { breast }\end{array}$ & $\begin{array}{l}\text { Reduction in } \\
\text { Salmonella choleraesuis } \\
\text { Reduction in oxidation and color } \\
\text { changes }\end{array}$ & Dias et al., 2013 \\
\hline $\begin{array}{l}\text { Semiconductor } \\
\text { nanocrystals }\end{array}$ & Polyethylene & Uncooked bacon & $\begin{array}{l}\text { (Smart packaging) } \\
\text { Oxygen nanosensors for } \mathrm{O}_{2} \text { detection } \\
\text { Assurance of package seal integrity }\end{array}$ & Mills, 2005 \\
\hline
\end{tabular}




\section{Nanolaminates: Edible coatings}

Nanolaminate used to cover food consists of more than one layer, and the materials are in the nanoscale (Weiss et al., 2006). Layer by layer (LbL) deposition techniques could be used to cover food which has surface charges (Kotov, 2003). An advantage of the LbL technique is that the thickness of the coating can be regulated with precision (1 to $100 \mathrm{~nm}$ ) (Weiss et al., 2006). Due to the extreme low thickness, it is better suited to be coated on food than as freely standing coatings (Kotov, 2003; Weiss et al., 2006). Along with serving as a barrier for gas or moisture, they can also carry antioxidants and antimicrobials. However, it is important to note that the properties of these edible coatings depended on the characteristics of the nanomaterials used in the layers (Weiss et al., 2006). Proteins, polysaccharides, and lipids are currently being used in the layers. Depending on the type of biopolymeric nanoparticles included in the coating, different functionality could be observed. Layers made of lipids act as barriers to moisture, but are not efficient to block gases and lack mechanical strength. On the other hand, protein and polysaccharide-based layers offer effective barriers against gases, but not moisture. Hence, nanolaminates can be used as natural edible barriers for the simultaneous extension of shelf-life and nutrition (Weiss et al., 2006).

\section{Nanotracers}

Since the production and use of engineered nanomaterials can lead to human exposure, hazards of the nanoparticles have to be controlled to reduce personal exposure. Nanotracers have the ability to monitor potential risks of exposure, thereby benefiting food safety and biosecurity (Diallo and Brinker, 2011). Nanotracers and nanomonitors can have diverse applications such as air quality monitoring, environmental monitoring and nanoparticle exposure assessment (Ultrafine and nanoparticle monitors, 2014). However, devices that monitor the release of nanomaterials in different environments such in places of nanomaterial production or reuse are limited (NSI, 2012). Nonetheless, a nanoparticle monitor such as Aerasense (Philips) is able to detect and quantify the concentration, surface area and size of nanoparticles in real-time. Exposure assessments on a personal level, monitoring of nanoparticle pollution at workplaces and tracing of particles sources can be achieved through the use of such devices (Marra et al., 2010). Therefore, nanotracers and nanomonitors can be applicable to assess the risks at every level of meat chains.

\section{POTENTIAL RISKS IN PROCESSING}

Although there are many potential benefits, concerns over the potential risks of using nanotechnology in the food industry have also been raised. Thus, to evaluate the safety of nanomaterials on cells, many tests have been undertaken, including oral toxicity, skin toxicity, and acute and chronic tests, as well as evaluation of the ability to cause mutagenesis and skin irritation (Cushen et al., 2012). It has been found that cytotoxicity, genotoxicity, oxidative stress, inflammation and other influences may be induced by the use of some nanomaterials in food applications (Cockburn et al., 2012). Metallic nanoparticles such as copper, zinc and titanium dioxides showed acute oral toxic effects in rodents at elevated dosage levels (Bouwmeester et al., 2009). The toxicity associated with biopolymeric nanoparticles such as PLGA was found to be minimal, but it lacked efficiency due to decreased loading capacity and increased burst release (Danhier et al., 2012). It is important to note that the differences in toxicity originating from free nanomaterials, biodegradable, or bound nanomaterials needs to be understood (Borm and Berube, 2008). Liposomes, which vary from micro to nanometers in size, are known to be biodegradable, and the association of toxicity with its use is uncommon (Underwood and Eps, 2012; Akbarzadeh et al., 2013). However, the cost of production, complicated preparation methodologies, and stability problems has impeded their utilization in foods (Underwood and Eps, 2012).

According to Cockburn et al. (2012), engineered nanomaterials may have different uptake kinetics compared to bulk materials. Especially, changes in interactions with the body can be expected when the nanomaterials have decreased solubility. On the other hand, features such as the size, charge, and shape of certain nanomaterials may also cause cytotoxicity. For example, a charged particulate nanomaterial can lead to poration of the lipid bilayers of cell membranes (Lovric et al., 2005). Inflammation may also be caused due to the accumulation of some particulate nanomaterials in immune cells. Nanomaterials may induce oxidative stress, also leading to inflammation. Increased levels of reactive oxygen species (ROS) can lead to the depletion of glutathione, an important antioxidant in cells. All of these mechanisms are often associated with toxicity. In addition, direct interaction between nanoparticles and genomic DNA can cause genotoxicity (Cockburn et al., 2012). Solid lipid nanoparticles and polymeric micelles have been reported to exhibit low levels of toxicity. While the use of nanoemulsions in food can be cost effective, some surfactants and solvents may have potential risks for human consumption (He et al., 2010; Underwood and Eps, 2012). Due to such diverse toxic effects among nanomaterials, a case by case assessment of risk would be beneficial (Bouwmeester et al., 2009; Cockburn et al., 2012). 


\section{POTENTIAL RISKS IN PACKAGING}

The area of food production wherein nanotechnology can have a great impact is in food packaging (Chaudhry and Castle, 2011). Studies have indicated that consumers are more willing to accept the presence of nanomaterials in packaging than in food (Siegrist et al., 2007). However, the nanomaterials in food packaging may potentially migrate to food, which in turn can be ingested or inhaled, or even be transferred through skin contact (Carlson et al., 2008). Studies on nanoparticles of titania, silver and CNTs have shown that these materials could enter blood circulation, and their insolubility may cause accumulation in organs (Gurr et al., 2005; Carrero-Sa'nchez et al., 2006; Kim et al., 2008; Rhim et al., 2013).

Based on a study by Avella et al. (2005), only a small amount of particle migration from nanocomposites to foods was seen during food packaging. This migration was within the limits prescribed by the European Commission (EC) for silica nanoparticles in clay nanocomposites. Similarly, studies on Ag and $\mathrm{ZnO}$ by Panea et al. (2013) also showed particle migration to be well below the limits set by the EC. On the other hand, a report shows that nanoparticles of $\mathrm{ZnO}$ may potentially lead to genotoxicity in epidermal cells at very less concentration (Sharma et al., 2009). Simon et al. (2008) reported that decreasing nanoparticle size and polymer viscosity resulted in an increase of the rate of migration in the system. In a study by Huang et al. (2011), the temperature at which the packaging was stored and the time were identified as two factors which influenced the amount of nanoparticle migration from the packaging. In addition, the use of some nanocomposites has raised concerns about environmental contamination, as they may not be bio-degradable. Eco-toxicity studies on such nanoparticles would significantly improve the acceptability of nanotechnology to consumers (Cushen et al., 2012). Even when some countries permit the release of compounds from packaging, the long term effects of some nanomaterials are not yet known (Cushen et al., 2012; Rhim et al., 2013). Hence, risk analysis encompasses risk assessment (scientific pursuit), management, communication and the interaction between these integral parts for ensuring the safety and security of public health (Bouwmeester and Marvin, 2010).

\section{REGULATION OF NANOTECHNOLOGY IN FOOD}

The United States, Japan, Germany, and China are currently leading the development of food products which apply nanotechnology (Helmut Kaiser Consultancy, 2009). Countries such as China may provide better open markets due to their underdeveloped regulatory systems (Chaudhry and Castle, 2011). In the United State, the challenges in regulation due to complexities in nanotechnology are further exacerbated by the lack of a single comprehensive regulatory framework (ensuring consumer safety) (Corley et al., 2009). The impediments in the analysis of risk originating from nanoproducts are limited information, insufficient models (reflecting real world) and uncertainties with respect to oversight by government agencies (Kuzma et al., 2008). The pace of risk assessment research is also making the regulation of nanomaterials a difficult undertaking. In addition, the safety assessment of food packaging has become essential to ensure safety, due to the potential migration of nanoparticles. Furthermore, with growing interest in nanotechnology, the development of nanoproducts has not kept up with the expectations of consumers about the safety of such products (Cushen et al., 2012). Nonetheless, the effectiveness of regulation in food depends on the comprehensiveness of definitions, and liabilities of products and applications that possess nanomaterials with novel and varied properties as well as the proper permitted levels pertaining to the nanomaterials (Chaudhry et al., 2010).

\section{PUBLIC ACCEPTANCE}

Public acceptance is imperative for the commercial success of any product (Siegrist et al., 2007). As seen in the case of genetically modified foods, acceptance can be hindered by concerns over health and environment (Gaskell et al., 1999). Consumers are expected to purchase products which are low-priced and offer more benefits, but reluctance was also seen towards the use of nanotechnology in food (Spence and Townsend, 2006; Siegrist et al., 2008). Siegrist et al. (2007) used the willing to buy (WTB) model to explain the factors influencing the acceptability of nanotechnology in food. It was found that affect heuristics played an important role in the perception of benefits and risks of novel products. Thus, gaining social trust and improving the perception of naturalness of nanoproducts could positively affect the WTB of such products (Siegrist et al., 2007). According to Cushen et al. (2012) on the public acceptance of nanotechnology in the United States, consumers were found to have limited knowledge about this technology, but an optimistic perception. Studies in Europe were less positive (Gaskell et al., 2005), while results in Taiwan were more positive when the perception of benefits was higher (Chen et al., 2013). Therefore, improving the knowledge and social trust among consumers could improve the public perception regarding the use of nanotechnology in food (Siegrist et al., 2007). In order to improve the public acceptance of food nanotechnology, major efforts to ensure the safety of nanofoods need to be undertaken by governments, manufacturers and concerned 
authorities (Chen et al., 2013)

\section{CONCLUSION}

Promising applications of nanotechnology may be in meat packaging, through systems which possess efficient barrier and antimicrobial properties as well as in meat processing through improvement of sensory characteristics, and nanoencapsulation of bioactive compounds. Other prospects include improvements in the nutrition and functional properties of meat products. However, the application of nanotechnology in meat remains a huge challenge. The application of nanoemulsions in meat products has faced problems such as oxidative instability and short-lived antimicrobial effects. The use of nanopowders is also hindered by the lack of efficient equipments for processing, along with the nature of the ingredients themselves. Other nanomaterials, depending on the type, have preparation methodologies which can be difficult, and lack scalability, performance efficiency and cost effectiveness. Potential health risks associated with the use of some nanomaterials is another major concern, but is dependent on the characteristics of the nanomaterials as well as the biokinetics of the human body in response to the materials. However, with increasing research activities, and development of associated technologies, instruments and methodologies, nanotechnology can significantly contribute to meat industries. Apart from filling the knowledge gaps in the production and safety of nanomaterials, improving public acceptance, economics and pragmatic regulation could be important for the successful future application of nanotechnology in meat products and packaging.

\section{ACKNOWLEDGMENTS}

This work was carried out with the support of "Cooperative Research Program for Agriculture Science \& Technology Development (Project No. PJ009848)" Rural Development Administration, Republic of Korea.

\section{REFERENCES}

Abdou, E. S., A. S. Osheba, and M. A. Sorour. 2012. Effect of chitosan and chitosan-nanoparticles as active coating on microbiological characteristics of fish fingers. Int. J. Appl. Sci. Technol. 2:158-169.

Akbarzadeh, A., R. Rezaei-Sadabady, S. Davaran, S. W. Joo, N. Zarghami, Y. Hanifehpour, M. Samiei, M. Kouhi, and K. Nejati-Koshki. 2013. Liposome: classification, preparation, and applications. Nanoscale Res. Lett. 8:102.

Althues, H., J. Henle, and S. Kaskel. 2007. Functional inorganic nanofillers for transparent polymers. Chem. Soc. Rev. 36: 1454-1465.

Augustin, M. A. and P. Sanguansri. 2009. Nanostructured materials in the food industry. Adv. Food. Nutr. Res. 58:183213.

Avella, M., J. J. De Vlieger, M. E. Errico, S. Fischer, P. Vacca, and M. G. Volpe. 2005. Biodegradable starch/clay nanocomposite films for food packaging applications. Food Chem. 93:467-474

Borm, P. J. A. and D. Berube. 2008. A tale of opportunities, uncertainties, and risks. Nano Today 3:56-59.

Borm, P. J. A., D. Robbins, S. Haubold, T. Kuhlbusch, H. Fissan, K. Donaldson, R. Schins, V. Stone, W. Kreyling, J. Lademann, J. Krutmann, D. Warheit, and E. Oberdorster. 2006. The potential risks of nanomaterials: A review carried out for ECETOC. Part. Fibre Toxicol. 3:11.

Bouwmeester, H., S. Dekkers, M. Y. Noordam, W. I. Hagens, A. S. Bulder, C. de Heer, T. S. E. Voorde, S. W. Wijnhoven, H. J. Marvin, and A. J. Sips. 2009. Review of health safety aspects of nanotechnologies in food production. Regul. Toxicol. Pharmacol. 53:52-62.

Bouwmeester, H. and H. J. P. Marvin. 2010. Potential risks of nanofood to consumers. In: Nanotechnologies in Food (Eds. Q. L. Chaudhry, L. Castle, and R. Watkins). Royal Society of Chemistry Publishers, Cambridge, UK. pp. 134-140.

Brody, A. L., B. Bugusu, J. H. Han, C. K. Sand, and T. H. Mchugh. 2008. Innovative food packaging solutions. J. Food Sci. 73: 107-116.

Carlson, C., S. M. Hussain, A. M. Schrand, L. K. Braydich-Stolle, K. L. Hess, R. L. Jones, and J. J. Schlager. 2008. Unique cellular interaction of silver nanoparticles: size-dependent generation of reactive oxygen species. J. Phys. Chem. B. 112: 13608-13619.

Carrero-Sánchez, J. C., A. L. Elías, R. Mancilla, G. Arrellín, H. Terrones, J. P. Laclette, and M. Terrones. 2006. Biocompatibility and toxicological studies of carbon nanotubes doped with nitrogen. Nano Lett. 6:1609-1616.

Chaudhry, Q., M. Scotter, J. Blackburn, B. Ross, A. Boxall, and L. Castle. 2008. Applications and implications of nanotechnologies for the food sector. Food Addit. Contam. 25: 241-258.

Chaudhry, Q., R. Watkins, and L. Castle. 2010. Knowns, unknowns and unknown unknowns In: Nanotechnologies in Food (Eds. Q. L. Chaudhry, L. Castle, and R. Watkins). Royal Society of Chemistry Publishers, Cambridge, UK. pp. 212-214.

Chaudhry, Q. and L. Castle. 2011. Food applications of nanotechnologies: An overview of opportunities and challenges for developing countries. Trends Food Sci. Technol. 22:595-603.

Chen, L. and M. Subirade. 2005. Chitosan/ $\beta$-lactoglobulin coreshell nanoparticles as nutraceutical carriers. Biomaterials 26:6041-6053.

Chen, M. F., Y. P. Lin, and T. J. Cheng. 2013. Public attitudes toward nanotechnology applications in Taiwan. Technovation 33:88-96.

Cockburn, A., R. Bradford, N. Buck, A. Constable, G. Edwards, B. Haber, P. Hepburn, J. Howlett, F. Kampers, C. Klein, M. Radomski, H. Stamm, S. Wijnhoven, and T. Wildeman. 2012. Approaches to the safety assessment of engineered nanomaterials (ENM) in food. Food Chem. Toxicol. 50:22242242.

Corley, E., D. A. Scheufele, and Q. Hu. 2009. Of risks and regulations: how leading U.S. nanoscientists form policy 
stances about nanotechnology. J. Nanopart. Res. 11:1573-1585.

Çubukçua, M., S. Timurb, and U. Anik. 2007. Examination of performance of glassy carbon paste electrode modified with gold nanoparticle and xanthine oxidase for xanthine and hypoxanthine detection. Talanta 74:434-439.

Cushen, M., J. Kerry, M. Morris, M. Cruz-Romero, and E. Cummins. 2012. Nanotechnologies in the food industry Recent developments, risks and regulation. Trends Food Sci. Technol. 24:30-46.

Danhier, F., E. Ansorena, J. M. Silva, R. Coco, A. L. Breton, and V. Préat. 2012. PLGA-based nanoparticles: An overview of biomedical applications. J. Control. Release 161:505-522.

de Azeredo, H. M. C. 2009. Nanocomposites for food packaging applications. Food Res. Int. 42:1240-1253.

Diallo, M. and C. J. Brinker. 2011. Nanotechnology for sustainability: Environment, water, food, minerals, and climate. In: Nanotechnology Research Directions for Societal Needs in 2020: Retrospective and outlook (Eds. M. C. Roco, C. A. Mirkin, and M. C. Hersam). Springer, London, UK. pp. 229.

Dias. M. V., N. F. Soares, S. V. Borges, M. M. de Sousa, C. A. Nunes, I. R. N. de Oliveira, and E. A. A. Medeiros. 2013. Use of allyl isothiocyanate and carbon nanotubes in an antimicrobial film to package shredded, cooked chicken meat. Food Chem. 141:3160-3166.

Duncan, T. V. 2011. Applications of nanotechnology in food packaging and food safety: Barrier materials, antimicrobials and sensors. J. Colloid Interface Sci. 363:1-24.

EFSA. 2009. Scientific opinion of the scientific committee. The potential risks arising from nanoscience and nanotechnologies on food and feed safety. EFSA J. 958:1-39.

Evans, H. M. 2009. Nanotechnology enabled sensing. Report of the national nanotechnology workshop, National Nanotechnolo-gical Initiative workshop. pp. 9, 27-34.

Fedotova, A. V., A. G. Snezhko, O. A. Sdobnikova, L. G. Samoilova, T. A. Smurova, A. A. Revina, and E. B. Khailova. 2010. Packaging materials manufactured from natural polymers modified with silver nanoparticles. Int. Polym. Sci. Technol. 37:59-64.

Fernandez, A., S. T. Giner, and J. M. Lagaron. 2009. Novel route to stabilization of bioactive antioxidants by encapsulation in electrospun fibers of zein prolamine. Food Hydrocol. 23: 1427-1432.

Flanagan, J. and H. Singh. 2006. Microemulsions: A potential delivery system for bioactives in food. Crit. Rev. Food Sci. Nutr. 46:221-237.

FSAI. 2008. The relevance for food safety of applications of nanotechnology in the food and feed industries. Food Safety Authority of Ireland. Dublin, Ireland. pp. 11.

Gaskell, G., M. W. Bauer, J. Durant, and N. C. Allum. 1999. Worlds apart? The reception of genetically modified foods in Europe and the US. Science, 285:384-387.

Gaskell, G., T. T. Eyck, J. Jackson, and G. Veltri. 2005. Imagining nanotechnology: cultural support for technological innovation in Europe and the United States. Public Underst. Sci. 14:81-90.

Graveland-Bikker, J. F. and C. G. de Kruif. 2006. Unique milk protein based nanotubes: food and nanotechnology meet. Trends Food Sci. Technol. 17:196-203.

Gruère, G. P. 2012. Implications of nanotechnology growth in food and agriculture in OECD countries. Food Policy 37:191-198.
Gupta, A. K. and M. Gupta. 2005. Synthesis and surface engineering of iron oxide nanoparticles for biomedical applications. Biomaterials 26:3995-4021.

Gurr, J. R., A. S. Wang, C. H. Chen, and K. Y. Jan. 2005. Ultrafine titanium dioxide particles in the absence of photoactivation can induce oxidative damage to human bronchial epithelial cells. Toxicology. 213:66-73.

He, C. X., Z. G. He, and J. Q. Gao. 2010. Microemulsions as drug delivery systems to improve the solubility and the bioavailability of poorly water-soluble drugs. Expert Opin. Drug Deliv. 7:445-460.

Helmut Kaiser Consultancy. 2009. Study: nanotechnology in food and food processing industry worldwide 2003-2006-2010 2015. HKC. http://www.hkc22.com/nanomarkets.html. Accessed February 6, 2014.

HOL (House of Lords). 2010. Nanotechnologies and food, volume I: Report. House of Lords, Science and technology committee, 1st report of Session 2009-2010, HL Paper 22-I, the Stationery Office, London, USA. pp. 12, 51-52.

Huang, Q., H. Yu, and Q. Ru. 2010. Bioavailability and delivery of nutraceuticals using nanotechnology. J. Food Sci. 75:50-57.

Huang, Y., S. Chen, X. Bing, C. Gao, T. Wang, and B. Yuan. 2011. Nanosilver migrated into food-simulating solutions from commercially available food fresh containers. Packaging Technol. Sci. 24:291-297.

IFIC (International Food Information Council). 2006. Functional foods. http://ific.org/nutrition/functional/index.cfm. Accessed March 14, 2014.

Joe, M. M., P. S. Chauhan, K. Bradeeba, C. Shagol, P. K. Sivakumaar, and T. Sa. 2012. Influence of sunflower oil based nanoemulsion (AUSN-4) on the shelf life and quality of IndoPacific king mackerel (Scomberomorus guttatus) steaks stored at $20^{\circ} \mathrm{C}$. Food Control 23:564-570.

Kotov, N. A. 2003. Layer-by-layer assembly of nanoparticles and nanocolloids: intermolecular interactions, structure and materials perspective. In: Multilayer Thin Films: Sequential Assembly of Nanocomposite Materials (Eds. G. Decher and J. B. Schlenoff). Wiley-VCH, Weinheim, Germany. pp. 207-243.

Kim, J. S., E. Kuk, K. N. Yu, J. H. Kim, S. J. Park, H. J. Lee, S. H. Kim, Y. K. Park, Y. H. Park, C. Y. Hwang, Y. K. Kim, Y. S. Lee, D. H. Jeong, and M. H. Cho. 2007. Antimicrobial effects of silver nanoparticles. Nanomed. Nanotechnol. Biol. Med. 3: 95101.

Kim, Y. S., J. S. Kim, H. S. Cho, D. S. Rha, J. M. Kim, J. D. Park, B. S Choi, R. Lim, H. K. Chang, Y. H. Chung, I. H. Kwon, J. Jeong, B. S. Han, and I. J. Yu. 2008. Twenty eight-day oral toxicity, genotoxicity, and gender-related tissue distribution of silver nanoparticles in Sprague-Dawley rats. Inhal. Toxicol. 20:575-583.

Kuzma, J., J. Romanchek, and A. Kokotovich. 2008. Upstream oversight assessment for agrifood nanotechnology: A case studies approach. Risk Anal. 28:1081-1098.

Lee, K. T. 2010. Quality and safety aspects of meat products as affected by various physical manipulations of packaging materials. Meat Sci. 86:138-150.

Linton, J. D. and S. T. Walsh. 2008. A theory of innovation for process-based innovations such as nanotechnology. Technol. Forecast. Soc. Change 75:583-594.

Lok, C. N., C. M. Ho, R. Chen, Q. Y. He, W. Y. Yu, H. Sun, P. K. 
Tam, J. F. Chiu, and C. M. Che. 2007. Silver nanoparticles: partial oxidation and antibacterial activities. J. Biol. Inorg. Chem. 12:527-534.

Lövenstam, G., H. Rauscher, G. Roebben, B. Sokull Klüttgen, N. Gibson, J. P. Putaud, and H. Stamm. 2010. Considerations on a Definition of Nanomaterial for Regulatory Purposes. Joint Research Center of the European Commission (JRC) Reference Reports. Publication Office of the European Union, Luxembourg. pp. 17-18.

Lovric, J., H. S. Bazzi, Y. Cuie, G. R. A. Fortin, F. M. Winnik, and D. Maysinger. 2005. Differences in subcellular distribution and toxicity of green and red emitting CdTe quantum dots. J. Mol. Med. 83:377-385.

Marra, J., M. Voetz, and H. J. Kiesling. 2010. Monitor for detecting and assessing exposure to airborne nanoparticles. J. Nanopart. Res. 12:21-37.

McClements, D. J. and J. Rao. 2011. Food-grade nanoemulsions: formulation, fabrication, properties, performance, biological fate, and potential toxicity. Crit. Rev. Food Sci. Nutr. 51:285330.

Mills, A. 2005. Oxygen indicator and intelligent inks for packaging food. Chem. Soc. Rev. 34: 1003-1011.

Möller, M., U. Eberle, A. Hermann, K. Moch, and B. Stratmann. 2009. Nanotechnology in the food sector. Zürich: TA-SWISS. pp. 47.

Moraru, C. I., C. P. Panchapakesan, Q. Huang, P. Takhistov, S. Liu, and J. L. Kokini. 2003. Nanotechnology: A new frontier in food science. Food Technol. 57:24-29.

Moraru, C. I., Q. Huang, P. Takhistov, H. Dogan, and J. L. Kokini. 2009. Food nanotechnology: current developments and future prospects. Global. Issues. Food Sci. Technol. 21:369-399.

Morones, J. R., J. L. Elechiguerra, A. Camacho, K. Holt, J. B. Kouri, J. T. Ramírez, and M. J. Yacaman. 2005. The bactericidal effect of silver nanoparticles. Nanotechnology 16: 2346-2353.

Neo, Y. P., S. Ray, J. Jin, M. Gizdavic-Nikolaidis, M. K. Nieuwoudt, D. Liu, and S. Y. Quek. 2013. Encapsulation of food grade antioxidant in natural biopolymer by electrospinning technique: A physicochemical study based on zein-gallic acid system. Food Chem. 136:1013-1021.

NSI. 2012. NSI white paper: Nanotechnology for sensors and sensors for Nanotechnology: Improving and protecting health, safety, and the environment, Nanotechnology Signature Initiative. NSI white paper 1-11.

NSI. 2013. Nanotechnology for sensors and sensors for Nanotechnology: Improving and protecting health, safety, and the environment. Nanotechnology Signature Initiative. http://www.nano.gov/node/849. Accessed March 17, 2014.

O'Brien, N. and E. Cummins. 2010. Ranking initial environmental and human health risk resulting from environmentally relevant nanomaterials. J. Environ. Sci. Health., Part A. 45: 992-1007.

Okutan, N., P. Terzi, and F. Altay. 2014. Affecting parameters on electrospinning process and characterization of electrospun gelatin nanofibers. Food Hydrocoll. 39:19-26.

Olmedilla-Alonsoa, B., F. Jiménez-Colmeneroa, and F. J. SánchezMuniz. 2013. Development and assessment of healthy properties of meat and meat products designed as functional foods. Meat Sci. 95:919-930.

Ozimek, L., E. Pospiech, and S. Narine. 2010. Nanotechnology is food and meat processing. Acta Sci. Pol. Technol. Aliment. 9: 401-412.

Panea, B., G. Ripoll, J. González, A. Fernández-Cuello, and P. Albertí. 2013. Effect of nanocomposite packaging containing different proportions of $\mathrm{ZnO}$ and $\mathrm{Ag}$ on chicken breast meat quality. J. Food Eng. 123:104-112.

Picouet, P. A., A. Fernandez, C. E. Realini, and E. Lloret. 2014. Influence of PA6 nanocomposite films on the stability of vacuum-aged beef loins during storage in modified atmospheres. Meat Sci. 96:574-580.

Ravichandran, M., N.S. Hettiarachchy, V. Ganesh, S.C. Ricke and S. Surendra. 2011. Enhancement of antimicrobial activities of naturally occurring phenolic compounds by nanoscale delivery against Listeria monocytogenes, Escherichia coli O157:H7 and Salmonella Typhimurium in broth and chicken meat system. J. Food Safety. 31:462-471.

Rhim, J. W., H. M. Park, and C. S. Ha. 2013. Bio-nanocomposites for food packaging applications. Prog. Polym. Sci. 38:16291652.

Salminen, H., K. Herrmann, and J. Weiss. 2013. Oil-in-water emulsions as a delivery system for n-3 fatty acids in meat products. Meat Sci. 93:659-667.

Semo, E., E. Kesselman, D. Danino, and Y. D. Livney. 2007. Casein micelle as a natural nano-capsular vehicle for nutraceuticals. Food Hydrocoll. 21:936-942.

Sharma, V., R. K. Shukla, N. Saxena, D. Parmar, M. Das, and A. Dhawan. 2009. DNA damaging potential of zinc oxide nanoparticles in human epidermal cells. Toxicol. Lett. 185:211-218.

Shibata, T. 2002. Method for producing green tea in microfine powder. United States Patent US6416803B1.

Shimoni, E. 2009. Nanotechnology for foods: delivery systems. In: IUFoST World Congress Book: Global Issues in Food Sci. Technol. pp. 411-424.

Siegrist, M., M. E. Cousin, H. Kastenholz, and A. Wiek. 2007. Public acceptance of nanotechnology foods and food packaging: The influence of affect and trust. Appetite 49:459466.

Siegrist, M., N. Stampfli, H. Kastenholz, and C. Keller. 2008. Perceived risks and perceived benefits of different nanotechnology foods and nanotechnology food packaging. Appetite 51:283-290.

Silvestre, C., D. Duraccio, and S. Cimmino. 2011. Food packaging based on polymer nanomaterials. Prog. Polym. Sci. 36:17661782.

Simon, P., Q. Chaudhry, and D. Bakos. 2008. Migration of engineered nanoparticles from polymer packaging to food $-\mathrm{a}$ physicochemical view. J. Food Nutr. Res. 47:105-113.

Sozer, N. and J. L. Kokini. 2009. Nanotechnology and its applications in the food sector. Trends Biotechnol. 27:82-89.

Spence, A. and E. Townsend. 2006. Examining consumer behavior toward genetically modified (GM) food in Britain. Risk Anal. 26:657-670.

Tan, C. P. and M. Nakajima. 2005. Beta Carotene nanodispersions: Preparation, characterization and stability evaluation. Food Chem. 92:661-671.

Troy, D. J. and J. P. Kerry. 2010. Consumer perception and the role of science in the meat industry. Meat Sci. 86:214-226.

Ultrafine and nanoparticle monitors. 2014. Philips Co. Inc. 
http://www.aerasense.com/index.php?pageID=3. March 13, 2014.

Underwood, C. and A. W. V. Eps. 2012. Nanomedicine and veterinary science: The reality and the practicality. Vet. J. 193: $12-23$.

USDA. 2008. Food safety information: additives in meat and poultry products. United States Department of Agriculture. http://www.fsis.usda.gov/wps/portal/fsis/topics/food-safetyeducation/get-answers/food-safety-fact-sheets/foodlabeling/additives-in-meat-and-poultry-products/additives-inmeat-and-poultry-products. Accessed November 3, 2014.

Villamizar, R., A. Maroto, R. F. Xavier, I. Inza, and M. Figueras. 2008. Fast detection of Salmonella Infantis with carbon analytical nanotechnology for food analysis 17 nanotube field effect transistors. Biosens Bioelectron. 24:279-283.

Weiss, J., P. Takhistov, and J. Mcclements. 2006. Functional materials in food nanotechnology. J. Food Sci. 71:107-116.

Weiss, J., M. Gibis, V. Schuh, and H. Salminen. 2010. Advances in ingredient and processing systems for meat and meat products. Meat Sci. 86:196-213.
Yam, K. L., P. T. Takhistov, and J. Miltz. 2005. Intelligent packaging: Concepts and applications. J. Food Sci. 70:1-10.

Yang, M, Y. Kostov, and A. Rasooly. 2008. Carbon nanotubes based optical immunodetection of Staphylococcal Enterotoxin B (SEB) in food. Int. J. Food Microbiol. 127:78-83.

Young, J. F., M. Therkildsen, B. Ekstrand, B. N. Che, M. K. Larsen, N. Oksbjerg, and J. Stagsted. 2013. Novel aspects of health promoting compounds in meat. Meat Sci. 95:904-911.

Yusop, S. M., M. G. O’Sullivan, M. Preuß, H. Weber, J. F. Kerry, and J. P. Kerry. 2012. Assessment of nanoparticle paprika oleoresin on marinating performance and sensory acceptance of poultry meat. LWT Food Sci. Technol. 46: 349-355.

Zhang, W., J. Zhang, Q. Jiang, and W. Xia. 2013. The hypolipidemic activity of chitosan nanopowder prepared by ultrafine milling. Carbohydr. Polym. 95:487-491.

Zhao, X., Z. Yang, G. Gai, and Y. Yang. 2009. Effect of superfine grinding on properties of ginger powder. J. Food Eng. 91:217-222.

Zhu, K., S. Huang, W. Peng, H. Qian, and H. Zhou. 2010. Effect of ultrafine grinding on hydration and antioxidant properties of wheat bran dietary fiber. Food Res. Int. 43:943-948. 